б) большой радиус и небольшое число электронов на внешнем энергетическом уровне,

в) малый радиус и небольшое число электронов на внешнем энергетическом уровне

Oтветь: б, а, а.

Постановка домашнего задания (3 мин.)

§34, упр. 1,2

6. Подведение итогов урока

Какие вопросы сегодня были рассмотрены на уроке?

1. Я понимал всё, о чём говорилось и, что делалось на уроке.

2. Я принимал активное участие в работе группы.

3. Мне было интересно.

4. Мне было не очень интересно.

Конспект урока- это четкий структурирования план проведения учебного занятия. Написание конспекта урока можно назвать подготовительным этапом работы учителя, конспект отражает педагогический замысел урока и является его сценарием. Данная разработка может быть использована на уроках химии.

1. Аршанский Е.Я. Методика обучения химии в классах гуманитарного профиля. - Москва: Гостехиздат, 2006. - 897 с.

2. Вискобойникова Н.П., Яшукова А.В. Настольная книга учителя. Химия. 9 кл.: Методическое пособие. - М.: Дрофа;

3. К Кузнецова Н.Е., Титова И.М., Гара Н.Н. под ред. проф. Н.Е. Кузнецовой. - 4 изд., переработ. - М, : Вентана-Граф, 2015-. - 288c.

\title{
Чернышова И.Е. \\ Разработка технологической карты урока по теме «Изменения в составе ядер атомов химических элементов. Изотопы»
}

ФГБОУ ВО «Самарский государственный соичиально-педагогический университет» (Россия, Самара)

doi: $10.18411 / \mathrm{j}-02-2021-44$

idsp: ljournal-02-2021-44

Научный руководитель

Сафина Л.Г.

Аннотация
Разработана $\quad$ технологическая $\quad$ карта $\quad$ комбинированного урока $\quad$ по

\footnotetext{
Abstract

The technological map of the combined lesson on the topic "Changes in the composition of atomic nuclei of chemical elements. Isotopes".

Key words: process map, a combined lesson.
}

В современном образовании главной задачей является объединить обучение, воспитание и развитие в единое целое. Одной из форм организации образовательного процесса является комбинированный урок - это универсальная форма, которая удобна для класса и предмета. На нем решаются дидактические задачи различных типов уроков, поэтому не стоит отказываться от него и за обилия новых форм и технологий. 
Гибкость и многообразие вариантов дает широкие возможности для использования новых приемов в его структуре.

В школьном курсе химии при изучении раздела «Атомы химических элементов» выделяется время на изучение темы «Изменения в составе ядер атомов химических элементов. Изотопы». Нами была разработана технологическая карта урока по этой теме. Разработанный комбинированный урок не только поможет при изучении данной темы, а также сформирует знания для дальнейшего обучения.

Цель занятия: сформировать представление об изотопах; дать современное определение понятия «Химический элемент».

В таблице 1 приведём подробную характеристику данного занятия.

Таблица 1.

Фрагмент технологической карты урока

\begin{tabular}{|c|c|}
\hline Деятельность учителя & Деятельность учащихся \\
\hline \multicolumn{2}{|c|}{ I. Вводная часть: организационный момент, контроль достижений учащихся (10 минут) } \\
\hline $\begin{array}{l}\text { Приветствие друг друга, запись в журнал } \\
\text { фамилии тех, кто отсутствует, проверка } \\
\text { готовности ребят к занятию. Настраивает } \\
\text { учащихся на учебную деятельность; } \\
\text { визуально проверяет готовность класса к } \\
\text { уроку; приветствует учащихся; отмечает } \\
\text { отсутствующих. } \\
\text { Проверяет уровень знаний по пройденной } \\
\text { теме (Приложение №1), контролирует. } \\
\text { Поясняет. }\end{array}$ & $\begin{array}{l}\text { Выполняют задания учителя. } \\
\text { Вспоминают сведения, полученные на прошлом уроке } \\
\text { изучение нового материала, систематизируют } \\
\text { информацию, дают ответ на поставленный вопрос. }\end{array}$ \\
\hline $\begin{array}{r}\text { II. Основная часть: актуализация и мотивация } \\
\text { материала; первич }\end{array}$ & $\begin{array}{l}\text { чебной деятельности; целеполагание; изучение нового } \\
\text { ный контроль и коррекция }\end{array}$ \\
\hline $\begin{array}{l}\text { 1. Мотивирует и стимулирует деятельность } \\
\text { учащихся (3 мин.): } \\
\text { Работа с П.С.: какими числами представлены } \\
\text { относительные атомные массы элементов? } \\
\text { Вопрос: Если масса атома определяется } \\
\text { количеством протонов и нейтронов, массы } \\
\text { которых выражены целым числом (единицей), } \\
\text { то почему Ar элементов представляют собой } \\
\text { дробные величины? } \\
\text { 2. Целеполагание (3 мин.) } \\
\text { Учитель: предлагает ответить на вопрос: } \\
\text { - Какова цель нашего урока? } \\
\text { Редактирует и озвучивает цель урока } \\
\text { 3. Изучение нового материала (10 мин.) } \\
\text { Вопросы: Что получится, если в ядре атома } \\
\text { изменить число протонов? Например, в ядро } \\
\text { атома кислорода добавить еще один протон. } \\
\text { Получится атомное ядро другого химического } \\
\text { элемента - фтора. } \\
\text { - А если из ядра атома кислорода убрать один } \\
\text { протон? } \\
\text { Получится атомное ядро химического } \\
\text { элемента - азота. } \\
\text { - Чего следует ожидать, если в ядре изменить } \\
\text { число других частиц - нейтронов? Можно ли } \\
\text { ожидать образование другого химического } \\
\text { элемента? } \\
\text { Нет, т.к. заряд ядра, т.е. число протонов в нем, } \\
\text { по условию не меняется. Следовательно, мы } \\
\text { получим разновидность того же самого } \\
\text { химического элемента, но уже с другим }\end{array}$ & $\begin{array}{l}\text { Формулируют цель урока. } \\
\text { Цель урока: сформировать понятие об изотопах, дать } \\
\text { современное определение понятия «Химический } \\
\text { элемент». } \\
\text { Отвечают на вопросы: }\end{array}$ \\
\hline
\end{tabular}




\begin{tabular}{|c|c|c|c|c|}
\hline $\begin{array}{l}\text { значением Ar - изотоп. Очевидно, теперь } \\
\text { стало понятным, почему в П.С. приведены не } \\
\text { целые, а дробные значения } \mathrm{Ar}-\text { все дело в } \\
\text { изотопах. } \\
\text { Пользуясь учебником, выписать определение } \\
\text { «изотопы» в тетрадь. (п.8 с.51) } \\
\text { Объясняет материал (Приложение №2). } \\
\text { Задает вопросы к классу: } \\
\text { Что произойдет с атомами одного и того же } \\
\text { вида, если в их ядра мысленно добавить по } 1 \\
\text { протону? } \\
\text { Теперь в ядро дейтерия добавьте один протон. } \\
\text { Сравните атом дейтерия и полученную } \\
\text { частицу. Какой заряд она имеет? Почему? } \\
\text { (Положительный, так как в атоме на один } \\
\text { электрон приходится два протона). }\end{array}$ & \multicolumn{4}{|c|}{$\begin{array}{l}\text { Учащиеся слушают } \\
\text { Отвечают на вопросы учителя. Записывают итоги } \\
\text { рассуждений. } \\
\text { Формулируют современную формулировку понятия } \\
\text { «химический элемент». }\end{array}$} \\
\hline \multirow{5}{*}{$\begin{array}{l}\text { Укажите состав изотопов углерода, заполнив } \\
\text { таблицу. }\end{array}$} & \multicolumn{4}{|c|}{ Заполняют таблицу. } \\
\hline & $\begin{array}{l}\text { Обозначение } \\
\text { атома }\end{array}$ & $\begin{array}{c}\text { Число } \\
\text { протонов }\end{array}$ & $\begin{array}{c}\text { Число } \\
\text { нейтронов }\end{array}$ & $\begin{array}{c}\text { Число } \\
\text { электронов }\end{array}$ \\
\hline & $\mathrm{C}$ & & & \\
\hline & $\mathrm{C}$ & & & \\
\hline & $\mathrm{C}$ & & & \\
\hline \multicolumn{5}{|c|}{ III. Заключительная часть: подведение итогов, рефлексия, домашнее задание (10 минут) } \\
\hline $\begin{array}{l}\text { Подведение итогов (3 мин.). } \\
\text { Отмечает активных обучающихся, } \\
\text { выставление отметок по результатам на уроке. } \\
\text { Рефлексия (5 мин.). Закончите предложение: } \\
\text { - я узнал... } \\
\text { - я научился... } \\
\text { - мне было легко... } \\
\text { - мне было сложно } \\
\text { Домашнего задания (2 мин). } \\
\text { Учить параграф 8. задание } 6 \text { после параграфа }\end{array}$ & \multicolumn{4}{|c|}{$\begin{array}{l}\text { Отвечают на вопросы. } \\
\text { Записывают домашнее задание в дневник. }\end{array}$} \\
\hline
\end{tabular}

\section{Приложение № 1}

1. Химический диктант.

Вариант 1 Вариант 2

1) Укажите «адрес» (номер, периода, группу и подгруппу) для элементов: Фосфор (Р), алюминий (Al)

2) Укажите название и химический знак элемента на основании его положения в П.С.: 3 период IIA группа 2 период VIIA группа

3) Определите число протонов для: сера (S), хром (Cr)

4) Определите число электронов для: калий $(\mathrm{K})$, углерод (C)

5) Определите число нейтронов для: фосфора $(\mathrm{P})$, калия $(\mathrm{K})$

2. КАРТОЧКА №1. 
1) Атом состоит из двух основных частей: и . Ядро состоит из

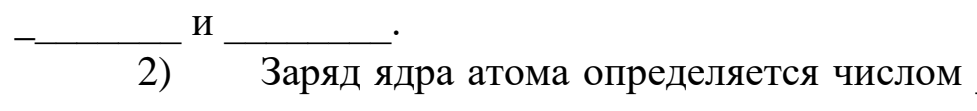
в его составе и не зависит от числа

3) Число электронов в атоме равно числу

4) Атом элемента с порядковым № 20 имеет электронов, протонов, _ـ нейтронов.

3. Фронтальный опрос: отвечают на вопросы:

— Что входит в состав ядер атомов?

- Как определить число протонов и электронов в ядре?

- Как определяется число нейтронов в ядре?

— Чему равен заряд и масса каждого из видов элементарных частиц?

\section{Приложение №2}

От слов «изос» - одинаковый, «топос» - место. Изотопы занимают одно место, одну клетку в ПСХЭ Д.И.Менделеева. Атомы изотопов одного элемента имеют одинаковое число протонов, но разное число нейтронов.

Каждый химический элемент встречается в природе в виде смеси изотопов. Атомные массы элементов, приводимые в ПСХЭ, есть среднеарифметические значения атомных масс природной смеси изотопов. Именно поэтому, они дробные.

По $\mathrm{Ar}$ можно предположить, какие изотопы существуют у данного элемента. Пример: $\operatorname{Ar}(\mathrm{K})=39,102$ (колеблется между 39 и 40). Следовательно, в природе встречаются 2 вида изотопов калия - с массовым числом 39, и с массовым числом 40. (39К и 40К). Очевидно, что подавляющее большинство природных изотопов калия (почти 90\%) приходится на долю «легких» изотопов 39К. А вот у аргона Ar, наоборот, больше тяжелых изотопов, поэтому значение его $\mathrm{Ar}$ близко к 40. $\mathrm{Ar}(\mathrm{Ar})=39,948$.

Для хлора характерны изотопы с массовыми числами не 35 и 36, а 35 и 37. Природный хлор состоит из 75\% изотопа с $\mathrm{Ar}=35$ и $25 \%$ изотопа с $\mathrm{Ar}=37$.

Зная, содержание каждого изотопа можно вычислить среднюю относительную атомную массу любого элемента.

\section{$\operatorname{Ar}(\mathrm{Cl})=35 \cdot 0,75+370,25=35,5$.}

Подобным образом, получаются атомные массы всех химических элементов, приведённых в ПСХЭ Д.И. Менделеева. Химические свойства изотопов одного и того же элемента одинаковые, т.к. они имеют один и тот же заряд ядра. Другое дело у изотопов водорода. Если у изотопов других элементов изменение масс незначительно, то в случае водорода масса изотопов меняется, увеличивается в 2,3 раза, поэтому это сказывается на свойствах элемента. Изотопы водорода имеют свои названия и обозначения:

$1 \mathrm{H}$ - протий; $2 \mathrm{H}$ - или D - дейтерий; $3 \mathrm{H}$-или Т - тритий

Разработанная технологическая карта поможет в проведении темы на уроке химии и внесет существенный вклад в формирование у учащихся основ научного мировоззрения.

\section{$* * *$}

1. Вербицкий А.А. Активное обучение в высшей школе: контекстный подход. М., 1991. 204 с.

2. Изучаем химию в 8 классе. Дидактическое пособие. Габриелян О.С., Смирнова Т.В. -М., 2002. 224c.

3. Комбинированный урок - как основной вид процесса обучения [Электронный ресурс] // Инфоурок - Режим доступа: https://infourok.ru/statya-na-temu-kombinirovanniy-urok-kak-osnovnoy-vid-processaobucheniya-3943876.html (Режим доступа: 18.01.2021)

4. Химия. 8 класс: учебник/ О.С. Габриелян. - 5-е изд., стереотип. - М.: Дрофа, 2016. - 287 с. 